\title{
Editorial
}

\section{Cells to Shells: The genomics of mollusc exoskeletons}

In our changing World there is a critical need for scientists to provide evidence-based analyses to underpin future predictions of ecosystem functioning, particularly with regard to food security and ecosystem services. Climate change is increasingly impacting on our daily lives and nowhere is this more prescient than the marine environment with the increasing acidification of the World's oceans, commonly known as Ocean Acidification (OA). This is predicted to particularly impact on organisms with calcareous skeletons as it is expected that any decrease in marine $\mathrm{pH}$ will significantly reduce these organisms' ability to precipitate calcium carbonate, which is central to constructing and maintaining robust skeletons and shells (reviewed in Doney et al. 2009). One phylum which relies heavily on calcification is the Mollusca. Molluscs are major elements of global benthic and plankton (larvae) ecosystems, comprising approximately $23 \%$ of marine species and include some of the World's most important commercial shellfish species, such as oysters and blue mussels. Their heavily calcified shells not only form their exoskeleton, but also provide their occupants with protection from both predators and harmful environmental agents, as well as a means of sealing the soft tissue away from fluid loss (Vermeij, 1983). To date, experimental manipulations of molluscs under different $O A$ scenarios have demonstrated a range of conflicting responses from the negative through to the positive (c.f. Ries et al. 2009).

To have an accurate predictive effect, these experiments have to be viewed within an ecological framework, which includes an understanding of the complexity of interactions between the genotype and the environment (c.f. Helmuth et al. 2010). These are important data, as the ability of organisms to respond to biotic and abiotic factors in their environment can result in the expression of highly variable phenotypes in the absence of genetic differentiation. This flexibility of response is often called phenotypic plasticity and can significantly impact on fitness and survival (c.f. Miner et al. 2005). In this respect, Molluscs are past masters at exploiting such plasticity to vary shell shape and thickness with habitat (e.g. Littorina striata: de Wolf et al. 1998; Littorina obtusata: Trussell and Nicklin, 2002; Siphonaria species: Teske et al. 2007; Isognomom alatus: Wilk and Bieler, 2009; Nacella concinna: Hoffman et al. 2010, Unio pictorum: Zieritz et al. 2010). Furthermore, a number of studies have proven causative links between production of thicker shells in response to damage by predators (e.g. Johannesson, 1986; Trussell and Smith, 2000) or environmental perturbation such as tidal emersion and ice impacts (e.g. Wilk and Beiler, 2009; Hoffman et al. 2010; Harper et al. 2012). So, given this inherent plasticity in shell production in a wide range of molluscs, the question arises, as to whether these animals can leverage this flexibility to overcome the effects of increasingly acidic sea water?

This is data we simply do not have and this is where genomics can really make an impact. The mechanisms underlying shell production are very poorly described (or absent) in most molluscs. The identification of calcium regulatory proteins and calcium pathways, including functional knowledge of calcium handling and turnover remains restricted to a handful of sequences, the favourite of which is carbonic anhydrase. This has been an obvious candidate gene ever since the first demonstration of this protein's catalytic ability to hydrate carbon dioxide in 1933 and its presence in the mantle tissue of molluscs 15 years later (Meldrum and Roughton, 1933; Freeman and Wilbur, 1948). However, the process of building a shell is clearly far more complex than the product of one gene.

Next Generation Sequencing technologies are significantly impacting on our ability to describe the genes present in the mantle that are associated with shell secretion in molluscs (Clark et al. 2010; Joubert et al. 2010; Zhang et al. 2012). However finding a gene is only the first step in a complex 
process and there is a pressing need to develop strategies and tools to understand how these biomineralization genes and proteins function and are regulated and also how these responses link to physiological processes and mineralogy. Without this fundamental knowledge of how marine organisms produce and maintain their skeletons or mobilise calcium in the face of environmental perturbation, we cannot begin to understand or predict the complex effects of life in an altered ocean environment and how to manage them for the benefit of aquaculture or indeed exploit such pathways and mechanisms in industrial processes.

This is the cornerstone of the CACHE (Calcium in a Changing Environment) Initial Training Network (http://www.cache-itn.eu). This network of young researchers is being trained in exploiting genomic and physiological technologies within a multidisciplinary ecological-based approach to answer the question of how molluscs produce shells. The network is focussed on four European major shellfish species; the blue mussel, Mytilus edulis, the Pacific oyster, Crassostrea gigas, the king scallop, Pecten maximus, and two soft-shelled clams, Mya arenaria and Mya truncata. These were chosen, not only for their commercial interest, but also the fact that they encompass a variety of shell mineralogy and microstructures. Both of which are important to study as these can have significant influence on both the energetics and ease of deposition of shells, and also the stability of shell structure under changing conditions. Consequently these species will each provide valuable case studies within which to conduct detailed mechanistic studies, while as a group, they encompass much of the variation in shell form and structure that is encountered in nature.

This young researcher-driven special issue (SI) of Marine Genomics starts with a review on Mytilus hybridization (Michalek et al. (2016-in this issue, pp. 3-7), the importance of understanding phenotypic plasticity, the underlying genotype and the impact on aquaculture. This is followed by two articles detailing the generation of mantle transcriptomic resources for the four species and the identification of biomineralization candidate genes and their associated SNPs (Yarra et al. (2016-in this issue, pp. 9-15; Vendrami et al (2016-in this issue, pp. 17-23). The next paper demonstrates the exploitation of mollusc sequence data to examine the fundamental processes of the evolution of calcium regulatory factors in metazoans (Cardoso et al. (2016-in this issue, pp. 25-35).

Both Bjärnmark et al. (2016-in this issue, pp. 37-45) and Sleight et al. (2016-in this issue, pp. 47-55) demonstrate the heterogeneous nature of the mantle tissue via the evaluation of RNA-Seq and candidate gene Q-PCR, whilst Hüning et al. (2016-in this issue, pp. 57-67) exploit a shell regeneration assay to uncover new biomineralization candidate genes. Transcriptomic data is also exploited in the proteomics approach of Arivalgan et al. (2016-in this issue, pp. 69-74) to identify shell matrix proteins that have a structural role but that may also play a role in defence.

In a more physiological approach (Sillanpää et al. (2016-in this issue, pp. 75-83) demonstrate the changes in calcium mobilisation from the environment following shell damage in the Pacific oyster, providing valuable baseline data for future transcriptomic analyses. The issue finishes with a review on biomimetic uses of shells (Morris et al. (2016-in this issue, pp. 85-90). This highlights the wider impact that fundamental research, including the types of data generated within the network, can have on the exploration of beneficial bio-inspired applications for societal gain. So, although the focus of this issue is on mollusc genomics, the articles really do encompass a wide range of disciplines from cells to shells.

This SI showcases the preliminary work of all the Early Stage Researchers (ESRs) and Experienced Researchers (ERs) employed within the CACHE network and also junior researchers employed within the member laboratories. Hence, it's a real first, both for the EU and Elsevier, as it is a special edition driven by the researchers of the future and exclusively contains their work. As Guest Editors, we hope that you find this issue very informative and inspirational. All of the young researchers in the 
network initiated and led the papers published here. Many are pilot studies, but provide valuable resources for the scientific community and highlight where their research is heading and the multidisciplinarity of their approach. It was particularly pleasing to see the generation of multiauthor papers encompassing different institutes which exemplifies the mobility and European networking ethos which underpins the Marie Skłodowska-Curie Actions (http://ec.europa.eu/research/mariecurieactions/).

\section{Acknowledgements}

The CACHE (Calcium in a Changing Environment) Initial Training Network was funded by the European Union Seventh Framework Programme, Grant number 605051. Project web site: http://www.cache-itn.eu. We would also like to acknowledge the invaluable support of our EU Project Officer Giuliana Donini; our Associated Partners: The Scottish Association of Shellfish Growers (ASSG: http://assg.org.uk/) and Coastal Research and Management (http://www.crmonline.de/); our International Advisory Experts: Professor Catherine Boyen and Professor Mike Thorndyke; Dr Guy Duke from the REA; our Artist-in-Residence, Rachel Ramirez, who created the wonderful cover illustration; the hosting institutions and all the reviewers that gave their valuable time to give decisive and helpful feedback on all the MS in this SI.

\section{References}

Clark MS, Thorne MAS, Vieira FA, Cardoso JCR, Power DM, Peck LS (2010) Insights into shell deposition in the Antarctic bivalve Laternula elliptica: Gene discovery in the mantle transcriptome using 454 pyrosequencing. BMC Genomics 11, 362.

De Wolf H, Backeljau T, Verhagen R (1998) Spatio-temporal genetic structure and gene flow between two distinct shell morphs of the planktonic developing periwinkle Littorina striata (Mollusca: Prosobranchia). Marine Ecology Progress Series. 163,155-163.

Doney SC, Fabry VJ, Feely RA, Kleypas JA (2009) Ocean Acidification: The Other $\mathrm{CO}_{2}$ Problem. Annual Review of Marine Science. 1, 169-192.

Freeman JA, Wilbur KM (1948) Carbonic anhydrase in molluiscs. Biological Bulletin. 94, 55-59. Harper EM, Clark MS, Hoffman JI, Philipp EER, Peck LS, Morley SA (2012) Iceberg Scour and Shell Damage in the Antarctic Bivalve Laternula elliptica. PLoS One. 7, e46341.

Helmuth B, Broitman BR, Yamane L, Gilman SE, Mach K, Mislan KAS, et al. (2010) Organismal climatology: analyzing environmental variability at scales relevant to physiological stress. Journal of Experimental Biology. 213, 995-1003.

Hoffman JI, Peck LS, Hillyard G, Zieritz A, Clark MS (2010) No evidence for genetic differentiation between Antarctic limpet Nacella concinna morphotypes. Marine Biology. 157, 765-78.

Johannesson B (1986) Shell morphology of Littorina saxatilis olivi - The relative importance of physical factors and predation. Journal of Experimental Marine Biology and Ecology. 102, 183-95. Joubert C, Piquemal D, Marie B, Manchon L, Pierrat F, Zanella-Cleon I, et al. (2010) Transcriptome and proteome analysis of Pinctada margaritifera calcifying mantle and shell: focus on biomineralization. BMC Genomics. 11, 613.

Meldrum NU, Roughton FJW (1933) Carbonic anhydrase. Its preparation and properties. Journal of Physiology. 80, 113-142.

Miner BG, Sultan SE, Morgan SG, Padilla DK, Relyea RA (2005) Ecological consequences of phenotypic plasticity. Trends in Ecology \& Evolution. 20, 685-92.

Ries JB, Cohen AL, McCorkle DC (2009) Marine calcifiers exhibit mixed responses to $\mathrm{CO}_{2}$-induced ocean acidification. Geology. 37, 1131-1134.

Teske PR, Barker NP, McQuaid CD (2007) Lack of genetic differentiation among four sympatric southeast African intertidal limpets (Siphonariidae): Phenotypic plasticity in a single species? Journal of Molluscan Studies. 73, 223-228. 
Trussell GC, Nicklin MO (2002) Cue sensitivity, inducible defense, and trade-offs in a marine snail. Ecology. 83, 1635-1647.

Trussell GC, Smith LD (2000) Induced defenses in response to an invading crab predator: An explanation of historical and geographic phenotypic change. Proceedings of the National Academy of Sciences of the United States of America. 97, 2123-2127.

Vermeij GJ (1983) Traces and trends of predation, with special reference to bivalve animals. Palaeontology.26, 455-465.

Wilk J, Bieler R (2009) Ecophenotypic variation in the Flat Tree Oyster, Isognomon alatus (Bivalvia: Isognomonidae), across a tidal microhabitat gradient. Marine Biology Research. 5, 155-163. Zhang GF, Fang XD, Guo XM, Li L, Luo RB, Xu F, et al. (2012) The oyster genome reveals stress adaptation and complexity of shell formation. Nature. 490, 49-54.

Zieritz A, Hoffman JI, Amos W, Aldridge DC (2010) Phenotypic plasticity and genetic isolation-bydistance in the freshwater mussel Unio pictorum (Mollusca: Unionoida). Evolutionary Ecology. 24, 923-938.

Melody S Clark

British Antarctic Survey, Natural Environment Research Council, High Cross, Madingley Road, Cambridge, CB3 OET, UK.

Corresponding author

E-mail address: mscl@bas.ac.uk

Deborah M Power

Centre of Marine Sciences, Universidade do Algarve, Campus de Gambelas, 8005-139, Faro, Portugal

Kristina Sundell

Swedish Mariculture Research Centre, Sea and Society, University of Gothenburg, S-405 30 Gothenburg, Sweden

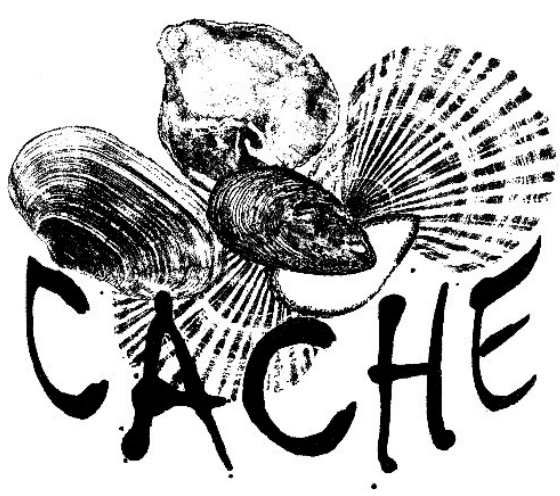

